\title{
ESPAÇOS NÃO FORMAIS DE EDUCAÇÃO COMO \\ CAMPO DE ATUAÇÃO DO LICENCIADO EM CIÊNCIAS \\ BIOLÓGICAS
}

Gustavo Lopes Ferreira

Universidade Federal de Uberlândia

Helena Morais Pacheco

Universidade Federal de Uberlândia

Luiz Paulo Costa e Silva

Universidade Federal de Uberlândia

Fernanda Helena Nogueira-Ferreira

Universidade Federal de Uberlândia

Daniela Franco Carvalho

Universidade Federal de Uberlândia

\begin{abstract}
Resumo
O texto promove reflexões acerca da formação em licenciatura em Ciências Biológicas de bolsistas integrantes do projeto de modernização do Museu de Biodiversidade do Cerrado da Universidade Federal de Uberlândia, buscando compreender a contribuição e as limitações dessa no preparo para a atuação em espaço não formal de educação. Percebeu-se que há uma dissonância entre o Projeto Político Pedagógico do curso e as ementas de algumas disciplinas como o Estágio Supervisionado, pois no projeto pedagógico fomenta-se uma formação que capacite o biólogo licenciado a atuar em espaços não formais de educação, porém as disciplinas abarcam de forma incipiente os saberes necessários para atuação nesses locais. Mesmo diante disso, os bolsistas agregaram saberes específicos para atuar em um museu de ciências, vivenciando-os na prática. $\mathrm{O}$ impacto dessa experiência sobre suas formações produziu uma identificação com o museu, o que lhes permitiu traçar direcionamentos futuros e prosseguirem atuantes nessa área.

Palavras-chave: Licenciatura em Ciências Biológicas; Espaços não formais de educação; Estágio Supervisionado.
\end{abstract}




\title{
NON- FORMAL EDUCATION SETTINGS AS A FIELD OF PRACTICE OF LICENSED IN BIOLOGICAL SCIENCES
}

\begin{abstract}
The text promotes reflections on formation in degree in Biological Sciences of fellows members of the modernization project of the Museum of Biodiversity of the Cerrado, Federal University of Uberlândia, trying to understand the contribution and limitations of this in preparation for operations in non-formal education setting. It was noticed that her is a dissonance between the Political Pedagogical Project Course and the menus of some subjects such as Supervised Trainee because the pedagogical projectfostersup training that empowers the biologist licensed to operate in non-formal education setting, but the incipiently disciplines encompass the knowledge needed to work in these places.Even at that, the scholars added specific knowledge to work in a science museum, experiencing them in practice.The impact of this experience on their formations produced identification with the museum, which allowed them to chart future directions and continue working in this area.
\end{abstract}

Key-words: Degree in Biological Sciences; Non-formal education setting; Supervised Trainee. 
Espaços não formais de educação como campo de atuação do licenciado em ciências biológicas Apresentação

O presente texto é uma tentativa de promover reflexões acerca da formação em licenciatura em Ciências Biológicas de bolsistas integrantes do projeto de modernização do Museu de Biodiversidade do Cerrado (MBC) da Universidade Federal de Uberlândia (UFU). Buscando compreender a contribuição epor vezes, as limitações desta no preparo para a atuação em espaço não formal de educação, no caso em um museu de ciências.

O MBC localiza-se na cidade de Uberlândia-MGe está integrado ao Parque Municipal VictórioSiquierolli que é uma unidade de conservação ambiental. É o único equipamento científico-cultural dessa natureza no Brasil e no mundo, voltado à popularização do conhecimento científico acumulado sobre temas do bioma Cerrado. Desde 2002, vinha mantendo basicamente a mesma estrutura física e as propostas de atividades de divulgação científica, apegado a uma exposição essencialmente contemplativa. Compreendendo um acervo didático de espécies animais representativas desse ecossistema em exposição permanente e um acervo científico de répteis, anfíbios, mamíferos, aves e invertebrados, resultante de pesquisas acadêmicas. No intuito de romper com a característica de um espaço onde os elementos museais se concentravam basicamente nas vitrines, pensouse num projeto de modernização e inserção de atividades interativas.

As características museográficas presentes na exposição do MBC no momento anterior à execução do projeto de modernização, alinha-se à proposta de Davallon (1986)apud Chelini e Lopes (2008), ou seja, permitiam o mero encontro do visitante com objetos, em que a "prioridade é ver, contemplar, estar em contato" com o que está exposto. É nesta feição expositiva que se circunscrevia o museu, enxergando o público como mero espectador dos objetos em exposição.

Com o projeto de remodelação intitulado "Modernização da Exposição Permanente e Diversificação das Estratégias de Divulgação

Olh@res, Guarulhos, v. 1, n. 2, p. 267-288, Novembro, 2013. 
Científica do Museu de Biodiversidade do Cerrado" "1 buscou-se inserir uma nova possibilidade de relacionamento do visitante com a exposição, ainda não explorada naquele espaço: a interatividade. Para isto, modificou-se tanto as instalações físicas, quanto a diversificação das propostas de atividades de divulgação científica ao público em geral.

A equipe proponente desse projeto foi formada por professores do Instituto de Biologia (INBIO) da Universidade Federal de Uberlândia, quatro bolsistas (uma de extensão, dois de apoio técnico e um de iniciação tecnológica e industrial), além de técnicos do INBIO/UFU. O detalhamento do projeto não se faz o foco da análise, partindo dessa desafiante experiência o texto mostra como alguns bolsistas se inseriram neste percurso e como esta caminhada contribuiu para a formação dos envolvidos.

Os bolsistas de extensão e de apoio técnico, licenciados em Ciências Biológicas, pela Universidade do Estado de Minas Gerais e Universidade Federal de Uberlândia, colaboraram na gestão do projeto, no sentido de promover uma interação entre a coordenação e os demais integrantes do grupo. Organizaram e acompanharam as atividades de modernização, registraram os dados e supervisionaram as atividades realizadas, buscando adequação destas e inter-relação do projeto como um todo no aspecto da extensão universitária. Colaboraram também no processo de aquisição dos itens constantes no orçamento.

O bolsista de Iniciação Tecnológica e Industrial, licenciando em Ciências Biológicas pela UFU, atuou na organização das vitrines e dos ambientes da exposição permanente, fornecendo manutenção dos animais taxidermizados, produzindo elementos de mostra e atrativos da área de exposição. Seu trabalho se ampliou por atuar como

\footnotetext{
${ }^{1}$ Aprovado com apoio financeiro do CNPq e FAPEMIG de no 559231/2009-1
}

Olh@res, Guarulhos, v. 1, n. 2, p. 247-268, Novembro, 2013. 
Espaços não formais de educação como campo de atuação do licenciado em ciências biológicas

colaborador na pesquisa de uma bolsista de Iniciação Científica Júnior $^{2}$, o que resultou na produção de artigos sobre divulgação científica e o ensino do bioma Cerrado.

Para este texto empreendeu-se reflexões sobre as percepções desses bolsistas entremeadas a suas formações acadêmicas em Ciências Biológicas, numa tentativa de averiguar como a temática educação em espaços não formais e divulgação científica se expressaram em suas vivências curriculares na graduação, e como esta exerceu papel limitador em suas preparações iniciais para atuarem no Museu de Biodiversidade do Cerrado.

\section{Repensando a formação acadêmica dos bolsistas}

Entendendo que alguns impasses vivenciados ao longo do trabalho no Museu de Biodiversidade do Cerrado estiveram relacionados diretamente com a formação inicial dos bolsistas integrantes, esse foi o ponto de partida para a reflexão. A crítica toma como base algumas disciplinas do Núcleo Pedagógico ${ }^{3}$ do currículo da licenciatura em Ciências Biológicas da Universidade Federal de Uberlândia. Tais componentes curriculares oficialmente são os responsáveis por oportunizar uma aproximação com os espaços não formais de educação, proporcionando uma fundamentação teórico-prática e entendendo esses espaços como campos de profissionalização do biólogo.

Espaço não formal de educação é um conceito muito debatido no cenário contemporâneo, não havendo um consenso sobre sua caracterização. Nesse campo controvertido, Jacobucci (2008) propõe uma ampliação do conceito, visto como "qualquer espaço diferente da

\footnotetext{
${ }^{2}$ Projeto intitulado: Avaliação e caracterização do ensino sobre o bioma Cerrado nas escolas de Ensino Infantil e Fundamental do município de Uberlândia-MG e a divulgação da temática em livros didáticos. Apoio financeiro FAPEMIG (Fundação de Amparo à Pesquisa do Estado de Minas Gerais).

${ }^{3}$ A saber as disciplinas de Projeto Integrado de Prática Educativa (1 a 7) e Estágio Supervisionado. Disponível em: <http://www.portal.ib.ufu.br/sites/ib.ufu.br/files/Anexos/Bookpage/Projeto\%20Pol\%C3\%ADtico\%20Ped ag\%C3\%B3gico\%20-\%20Curr\%C3\%ADculo\%202006-1.pdf>
}

Olh@ res, Guarulhos, v. 1, n. 2, p. 267-288, Novembro, 2013. 
escola onde pode ocorrer uma ação educativa", incluindo assim os: Museus, Centros de Ciências,Parques Ecológicos, Parques Zoobotânicos, Jardins Botânicos, Planetários, Institutos de Pesquisa,Aquários, Zoológicos, dentre outros. Diante disso, percebese que o contato e o aprendizado das ciências naturais não se "limitam mais ao contextoestritamente escolar”, como indica Queiroz (2002). Os saberes oriundos da ciência influenciam a vida dos cidadãos, conforme Wagensberg (2002), estes são responsáveis por formar intelectual, técnica e cientificamente os sujeitos, servindo desta maneira para que entendam a realidade e a partir dela possam tecer críticas. Nesse sentido, percebe-se a ampliação dos espaços de contato com os discursos da ciência (CUNHA \& GIORDAN, 2009) o que traz a cena outros modos de se perceber e relacionar com os conhecimentos científicos, que chegam cada vez mais rápidos ao público, por meio de diferentes mídias.

É neste contexto que os museus de ciências têm seu lugar de destaque ao firmarem o compromisso com a divulgação da Ciência. Cabe, portanto, pensar a formaçãodos profissionais para atuarem nesses espaços. De antemão pode-se afirmar o que outros trabalhos relataram, apresentando a escassez ou a quase inexistência no Brasil de uma formação específica para a área de divulgação científica, em museus de ciências (SOUZA, 2008; OVIGLI, 2011).

Os cursos de formação inicial de professores em áreas científicas, como o de Ciências Biológicas seguem a tendência de darem maior ênfase ao ensino formal, entendendo a escola como espaço fundamental e único para a formação docente(OVIGLI e FREITAS, 2009). Aqui se toma por referência o curso de Ciências Biológicas, por ser esta a área básica de formação dos bolsistas do projeto de modernização.

Diante disso para proceder à reflexão, recorreu-se ao Projeto Político Pedagógico e ementas das disciplinas Projetos Integrados de 
Espaços não formais de educação como campo de atuação do licenciado em ciências biológicas

Práticas Educativas (PIPE) e Estágio Supervisionado do curso de Biologia da Universidade Federal de Uberlândia. Esta é uma tentativa de traçar o que oficialmente está expresso na estrutura curricular, o que efetivamente foi realizado e qual o impacto produzido na formação dos estudantes.

Em leitura atenta do projeto pedagógico ${ }^{4}$ dá-se a entender, ainda que de modo sutil, que o estudante estará capacitado para atuar em espaços não formais de educação, uma vez que o curso propõe formar profissionais para atuarem como biólogos e pesquisadores nas diversas áreas das Ciências Biológicas e na docência no Ensino Fundamental e Médio. E ainda prevê fornecer amplas noções sobre Ensino de Ciências e Biologia em espaços formais e não formais de educação ${ }^{5}$. Isto é evidenciado pelo trecho seguinte, retirado do Projeto Político Pedagógico do curso, que explicita que o egresso será:

\begin{abstract}
Capacitado, com base no rigor científico e intelectual, para a geração do conhecimento e para o exercício de atividades referentes ao ensino de Ciências Biológicas, consciente de seu papel como educador nos vários contextos de atuação profissional e de sua responsabilidade como elemento gerador de novos conhecimentos. (Projeto Político Pedagógico do curso de Ciências Biológicas-UFU, p.12; grifo nosso).
\end{abstract}

Entendemos que os museus de ciências, assim como os demais espaços não formais de educação inserem-se nesses vários contextos de atuação do profissional graduado na área de Ciências Biológicas. Sendo, para isso, imprescindível que se conheça de forma profunda os conceitos/métodos/práticas que norteiam as ações educativas nesses espaços.

No mesmo documento, evidencia-se a estrutura curricular do curso articulada em dois núcleos: Específico e Pedagógico. O primeiro conta com 1800 h/a e reúne as disciplinasespecíficas da área de Ciências, com ênfase nos conteúdos biológicos. O segundo, com carga

\footnotetext{
${ }^{4}$ Disponível em: <http://www.portal.ib.ufu.br/sites/ib.ufu.br/files/Anexos/Bookpage/Projeto\%20Pol\%C3\%ADtico\%20Ped ag\%C3\%B3gico\%20-\%20Curr\%C3\%ADculo\%202006-1.pdf>

5 Informações retiradas do portal do curso de Biologia na internet. Disponível em: <http://www.portal.ib.ufu.br/node/56>
}

Olh@res, Guarulhos, v. 1, n. 2, p. 267-288, Novembro, 2013. 
horária de 1020 h/acompreende, além das disciplinas de natureza pedagógica, os Projetos Integrados de Práticas Educativas - PIPE e o Estágio Supervisionado. Este subdividido em Introdução ao Estágio, Estágio 1 e Estágio 2.

Aqui se evidencia as disciplinas do Núcleo Pedagógico, especificamente PIPE e o EstágioSupervisionado, por serem estas as responsáveis por abarcarem os estudos relacionados a espaços extraescolares, como bem ilustra o seguinte trecho do Projeto Pedagógico:

(...) esses componentes curriculares serão desenvolvidos de modo a possibilitar a análise fundamentada dos processos educativos que se desenvolvem em contextos escolares e não escolares, pois estes são campos de atuação profissional desse professor. (Projeto Político Pedagógico do curso de Ciências Biológicas-UFU, p.21; grifo nosso).

Embora haja a evidência de que os processos educativos se desenvolvam em contextos escolares e não escolares, ao observarmos as ementas das disciplinas de PIPE e Estágio Supervisionado, percebese que há uma prioridade das ações direcionadas ao contexto escolar, conduzindo ao entendimento de que é nesse ambiente que se efetua a prática pedagógica de forma privilegiada e muitas vezes única.

Do primeiro ao sétimo período do curso vivencia-se o PIPE com diversas temáticas ligadas ao ensino de Ciências e Biologia: Biologia e Educação (PIPE 1), Ciências Físicas e Químicas (PIPE 2), Biologia Celular e do desenvolvimento (PIPE 3), Genética e Ciências do Ambiente (PIPE 4), Zoologia (PIPE 5), Botânica (PIPE 6), Apresentação e divulgação das experiências vivenciadas nos PIPE's anteriores (PIPE 7). Como norte dessas ações busca-se consonância com oprincípio da articulação teoria-prática pedagógica, articulando saberes específicos/técnicos com o saber docente/do fazer pedagógico. Entendemos que essa articulação dos saberes específicos e técnicos com o saberes pedagógicos se dê em diferentes contextos escolares e não escolares, mas ao nos depararmos com as atividades a serem desenvolvidas nas disciplinas de PIPE descritas no Projeto Pedagógico, verifica-se uma ênfase no ambiente escolar:

Olh@res, Guarulhos, v. 1, n. 2, p. 247-268, Novembro, 2013. 
Espaços não formais de educação como campo de atuação do licenciado em ciências biológicas

A observação e a sua própria integração ao contexto das escolas;

A identificação, a análise e a busca de alternativas para situações-problema do cotidiano escolar. (Projeto Político Pedagógico do curso de Ciências BiológicasUFU, p.21).

Essa ênfase no espaço escolar também pode ser percebida no enfoque dos Estágios Supervisionados. Segundo o projeto pedagógico esse componente é "organizado e desenvolvido de modo a darcontinuidade aos Projetos de Prática Educativa e a eles integrar-se". É compreendido como mais um espaço de aproximação e integração do aluno com a realidade educacional, com o objeto de conhecimento e o campo de trabalho do professor de Ciências da $5^{\mathrm{a}}$ à $8^{\mathrm{a}}$ série do Ensino Fundamental e do professor de Biologia no Ensino Médio.Como se percebe, também é dado maior destaque aos aspectos da educação formal, fazendo desta realidade o campo de debate e desenvolvimento de ações dessas disciplinas, tal qual expressa suas ementas:

\footnotetext{
Aplicação de uma prática docente reflexiva, interventiva e formadora no campo do Estágio em Ciências no Ensino Fundamental e Biologia no Ensino Médio visando a construção própria de um modelo didático (...). (Ementas das disciplinas de Estágio I e II do curso de Ciências Biológicas- UFU; grifo nosso).
}

Confrontando-se o Projeto Político Pedagógico do curso com as ementas dessas disciplinas percebe-se uma dissonância. Pois, o projeto pedagógico, documento oficial que sedimenta as ações do curso, expressa que se formem profissionais para atuar em espaços não formais, como isso se efetivará se as disciplinas não abarcam os saberes necessários a esta formação?

Afirmamos, assim como aponta Martha Marandino (2003), que é preciso ampliar os espaços formativos dos professores:

Não se trata, assim, de negar o papel crucial que a escola possui na formação do professor, mas sim de compreender que ser profissional professor hoje engloba também o profundo conhecimento das diferentes práticas pedagógicas desenvolvidas em outros espaços educativos como, por exemplo, os museus de ciências. (MARANDINO, 2003, p.72).

Olh@ res, Guarulhos, v. 1, n. 2, p. 267-288, Novembro, 2013. 
Essa disjunção entre o que almeja tal documento e o que efetivamente vivencia-se nas práticas cotidianas do currículo, colocou alguns entraves no trabalho dos bolsistas que se sentiram em muitos momentos no museu despreparados ao enfrentarem situações que envolvia a dimensão da prática pedagógica em um ambiente não escolar.

A experiência dos bolsistas vivenciadas ao longo de disciplinas obrigatórias e eletivas durante o curso de Ciências Biológicas mostra que de forma pontual foram realizados alguns esforços de se ampliar as ações educativas para espaços extraescolares, principalmente, por meio de experiências em parques municipais ${ }^{6}$. Essas ações se deram principalmente nas disciplinas de Estágio Supervisionado e foram centradas na visão de que é importante para a formação inicial do professor de Ciências e Biologia o contato com os espaços não formais, na perspectiva da docência nesses locais ser efetivada por meio de saídas a campo, aulas experimentais ou desenvolvimento de projetos investigativos em contato com a natureza. Em nenhum momento as disciplinas focaram a formação do licenciado em Ciências Biológicas para atuação junto às equipes técnicas dos espaços não formais de educação. Ou seja, pensa-se a profissionalização do biólogo licenciado exclusivamente para atuação em sala de aula.

Consideramos que o Estágio é um momento fecundo para a experimentação com os diversos campos de profissionalização do futuro licenciado, pois se compreende que as práticas educativas podem se efetivar em outras instâncias que não só as escolas, como também, por exemplo, em museus de ciências. É preciso estimular e

\footnotetext{
${ }^{6}$ Parque Natural Municipal VictórioSiquierolli, Parque Municipal Santa Luzia e Parque do Sabiá - todos localizados na cidade de Uberlândia-MG.
}

Olh@res, Guarulhos, v. 1, n. 2, p. 247-268, Novembro, 2013. 
Espaços não formais de educação como campo de atuação do licenciado em ciências biológicas

oportunizar o engajamento de estudantes de licenciatura em estágios ainda durante a graduação em outros campos, destaque aqui para os espaços como os museus.

O grupo de bolsistas inclui-se nessa formação incipiente, cujo foco não está nos espaços não formais e na divulgação científica. Dessa forma, seus olhares para as propostas de modernização do MBC, num primeiro momento, se concentrou numa visão escolarizada do fazer docente, que limitou a criatividade das propostas educativas, pois se pensava o museu somente para o público escolar.

Agregando-se a isto, a equipe de trabalho atuante no projeto, não se constituiu de forma multidisciplinar. Devido à falta de profissionais de diversas áreas e o desafio inicialmente proposto, os bolsistas buscaram suprir essa demanda utilizando-se de várias alternativas: conhecimentos empíricos, consulta à literatura, acesso a sites de outros museus do Brasil e exterior, participação em eventos da área. Além disso, os bolsistas realizaram visitas a museus locais, nacionais e internacionais para formação de uma referência visual e prática sobre os espaços não formais de educação.

Pensando sobre isso o trabalho de Marília Cury (2002) mostra que o ponto fraco dos recursos humanos, está na especialização/capacitação/treinamento específicos para atuação em museus de ciências. Ainda alerta que estes espaçostêm consciência dessa fragilidade de capacitação profissional dos que estão atuando junto a essas instituições. Na tentativa de suprirem tal deficiência os profissionais encaram a tarefa de aprenderem na prática, como aconteceu com os bolsistas deste trabalho.

Como ação inicial dos bolsistas, houve a necessidade de uma remodelação para melhor aproveitamento do espaço do museu e disposição do acervo. Para isto, foram elaboradas duas propostas, expostas aos coordenadores do projeto e funcionários do museu. Essas ideias foram condensadas na forma de três plantas baixas 
confeccionadas manualmente, pelo fato não estar disponível naquele momento a planta arquitetônica original.

Em uma das plantas demonstrava-se a organização do museu naquele momento, as outras duas apresentavam novas alternativas diferentes da original. A proposta escolhida foi a que reorganizou a disposição das vitrines baixas próximas às janelas e vitrines altas dispostas nas paredes, possibilitando assim uma melhor visualização tanto das vitrines como também da parte externa do museu, davegetação em torno do parque.

As dificuldades enfrentadas não se limitaram ao reordenamento do espaço físico, que possivelmente se realizado por um profissional da área de design ou arquitetura ganharia outra conformação. $\mathrm{O}$ desafio maior foi o de pensar propostas interativas, que escapassem da velha visão de que os museus são espaços de silêncio e do "não toque", para isso foi preciso muita pesquisa e troca de ideias entre os participantes do projeto. Desta forma, foi possível implementar alguns artefatos interativos, que buscaram o envolvimento do público com a exposição, dentre esses a inserção de telas touchscreencom atividades em que é possível ouvir cantos de diversas aves do bioma Cerrado, módulos que desafiam o visitante a encontrar respostas, além de perguntas-desafiadoras que requerem que o público preste muita atenção na exposição a fim de resolve-las.

Outros desafios surgiram e foram enfrentados, como: a escolha de materiais adequados na reforma das vitrines para se alcançar um resultado esteticamente moderno e a falta de mão de obra especializada e comprometida com a entrega dos serviços nos prazos e condições estabelecidas. Apesar de tais dificuldades enfrentadas na prática em espaços não formais e as que surgiram durante a execução do trabalho, verifica-se que a ideia inicial do projeto foi aplicada, buscando atender aos objetivos levantados e aos desafios propostos. Após lidar com todo esse aprendizado, os bolsistas constantemente buscaram uma formação diferente da graduação,

Olh@res, Guarulhos, v. 1, n. 2, p. 247-268, Novembro, 2013. 
Espaços não formais de educação como campo de atuação do licenciado em ciências biológicas

pautando-se no trabalho em equipe, como ponto de partida das ações, entendendo a diversidade de ideias como fecundo momento de criação. Tal reflexão faz-se presente no trabalho de Souza (2008):

Parece-nos que a necessidade de trabalhar em equipe, os desafios encontrados, a busca por atividades inovadoras $\mathrm{e}$, inclusive, as dificuldades encontradas no processo de trabalho são fatores que unem os membros da equipe. Unidos em prol de um objetivo comum, os membros se fortalecem em conjunto na busca de soluções. (p.93).

Ao empreender uma reflexão acerca da constituição da equipe de trabalho envolvida no projeto de modernização do $\mathrm{MBC}$, percebe-se que a formação dos recursos humanos é de extrema importância para o sucesso das práticas educativas desses locais. Tal equipe foi constituída predominantemente por pessoas ligadas à área de biologia, fato relevante que em certos momentos requereu um maior esforço do grupo para superar visões monolíticas na proposição das atividades para o museu.

Mesmo diante do impasse imposto pela formação acadêmica inicial, os bolsistas aventuraram-se no árduo trabalho de aglutinar os saberes específicos para atuar nesse espaço, vivenciando-os na prática. $\mathrm{O}$ trabalho de Marília Cury (2002) sobre museus de ciências debate de forma abrangente tal reflexão aqui empreendida:

De fato, as situações de capacitação/treinamento foram poucas e temos que considerar a pequena disponibilidade de oportunidades nessa área. Por outro lado, temos algumas citações de profissionais que “aprenderam na prática”. Essa prática associada ao comprometimento das pessoas e a uma orientação especializada poderia resultar em ganhos positivos para as instituições e, principalmente para o público (p. 66 e 67; grifo nosso)

As experiências dos bolsistas remetem a necessidade de uma formação mais ampla no curso de licenciatura em Ciências Biológicas de forma a agregar de fato os espaços não formais de educação no cotidiano do futuro professor de Ciências e Biologia, não somente para complementação de sua prática docente, mas fundamentalmente 
Gustavo Lopes Ferreira, Helena Morais Pacheco, Luiz Paulo Costa e Silva, Fernanda Helena Nogueira-Ferreira \& Daniela Franco Carvalho

para evidenciar que a ação profissional em um museu de ciências pode ser observada como campo de atuação do biólogo licenciado.

\section{O potencial da proposta de modernização do Museu de Biodiversidade do Cerrado}

Partindo das experiências acumuladas na trajetória do projeto de modernização do $\mathrm{MBC}$, os bolsistas envolvidos sentiram-se encorajados a prosseguir atuantes na área de museus. Com esta vivência puderam ampliar sua formação acadêmica inicial, fato que os levaram a traçarem encaminhamentos futuros, alguns em via de concretização e outros ainda em amadurecimento.

No primeiro relato presencia-se como a criação de um espaço voltado ao público infantil impactou os planos de ação de uma bolsista, o segundo trata a respeito de como o envolvimento no projeto articulouse a uma pesquisa de iniciação científica e posteriormente em uma monografia. E por fim, apresenta-se uma pesquisa de mestrado em andamento envolvendo o museu, recém-iniciada por um dos bolsistas em um Programa de Pós-graduação em Educação.

As estratégias educativas tradicionais, principalmente no ambiente escolar, tendem a restringir a criatividade e a autonomia das crianças, propondo, muitas vezes, atividades diretivas e descontextualizadas. Tais práticas desenvolvem-se em detrimento de atividades que ampliem e diversifiquem seu desenvolvimento criativo e crítico. Nesse sentido considera-se que a aprendizagem em espaços não formais como os museus podem ensinar, principalmente, ciências naturais de modo a favorecer a criatividade e autonomia da criança, que nesses espaços podem escolher o que querem aprender, o que vão fazer e com o que irão interagir. Isto se dá porque nos museus e em outros espaços não escolares é possível que haja aprendizado por livre escolha conduzido pelasnecessidades e interesses de cada pessoa (DIERKING, 2005). Assim os museus se tornam fortes aliados das

Olh@res, Guarulhos, v. 1, n. 2, p. 247-268, Novembro, 2013. 
Espaços não formais de educação como campo de atuação do licenciado em ciências biológicas salas de aula na construção do discurso científico destes sujeitos (CUNHA \& GIORDAN, 2009).

Pensando nisso e considerando a importância da participação dos mais jovens nos espaços não formais de educação, o grupo participante do projeto de modernização do $\mathrm{MBC}$ desenvolveu um espaço dedicado, especialmente, às crianças, assim chamado "Espaço Infantil". Esse espaço foi criado com o intuito de atender a um público específico, onde os móveis são adequados ao universo infantil: banquetas multicoloridas, mesas em formatos de copa de árvores, pegadas coloridas de diversos animais do Cerrado, estante de livros e jogos em altura compatível ao alcance das crianças, contação de histórias utilizando animais confeccionados em feltro e fantoches.

Dentre todas as atividades propostas pelo grupo, a criação desse espaço exclusivamente dedicado às crianças foi determinante para despertar novas ideias na bolsista de extensão integrante do projeto. Isto se deu pelo fato de que esta trabalha na educação infantil, o que intensificou o seu interesse em seguir com essa linha de atuação. Partindo disso, sentiu a necessidade de ampliar sua experiência no âmbito de uma pós-graduação, lidando com a educação e percepção das crianças em relação a Ciências ao estarem em contato com esse local. Neste momento, dedica-se a leituras sobre o assunto e a pesquisar programas de pós-graduação que melhor satisfaçam seu objetivo.

Propõe ainda quem sabe investir em uma segunda graduação, no curso de Pedagogia, um momento em que poderá aliar seus conhecimentos advindos do trabalho no MBC com a melhoria dos processos de aprendizagem dos alunos em sala de aula, comprometendo-se em aguçar desde a Educação Infantil o interesse pelo conhecimento científico vivenciado em espaços extraescolares. Desta forma, procurará ampliar as possibilidadesde como professora possa vir atuar para além da sala de aula.

Olh@res, Guarulhos, v. 1, n. 2, p. 267-288, Novembro, 2013. 
Consideramos assim como Bridi (2011, p.11373) que a iniciação científica é o momento que o estudante extrapola as disciplinas curriculares, ou seja, é um espaço para a "concretização de novas formas curriculares". Admite-se que a iniciação científica contribui de maneira diferente e única para a formação do aluno, já que colabora tanto na formação ampla e cultural do universitário quanto na formação específica de pesquisador.

Nessa perspectiva o bolsista de iniciação tecnológica e industrial, único integrante do grupo ainda estudante do curso de graduação em Ciências Biológicas, ao contrário dos demais bolsistas, teve a oportunidade de vivenciar uma formação acadêmica diferenciada, por conviver, pesquisar e atuar em um museu. Assim o bolsista pôde vivenciar na prática o tripé da formação universitária, conforme Martins (2007): o ensino (por relacionar-se com os produtos da ciência enquanto graduando do curso de Ciências Biológicas), a pesquisa (por esta atividade relacionar-se diretamente a seu desenvolvimento, sendo instrumentalizado para a produção de conhecimentos) e a extensão (ao retornar à sociedade por meio do MBC os resultados de seu trabalho).

No decorrer do projeto, teve a oportunidade de auxiliar diretamente uma estudante do Ensino Médio, bolsista de Iniciação Científica Júnior (PIBIC/Jr)em uma pesquisa sobre o ensino do Cerrado e a divulgação deste nas escolas do município de Uberlândia-MG, atuando como mentor deste trabalho, o que lhe permitiu obter uma vivência sobre o universo da pesquisa no meio acadêmico.

A participação nos projetos de remodelação do MBC e de divulgação do Bioma Cerrado será utilizada no trabalho de monografia do bolsista, em fase de confecção. Considerando a imensa importância do Bioma Cerrado e a carência de estudos sobre a divulgação científica dessa temática na literatura científica, o bolsista sentiu a necessidade e a relevância de continuar com a pesquisa nessa área, contribuindo para a divulgação e ampliação dos conhecimentos

Olh@ res, Guarulhos, v. 1, n. 2, p. 247-268, Novembro, 2013. 
Espaços não formais de educação como campo de atuação do licenciado em ciências biológicas

adquiridos no MBC para comunidade científica e a população em geral.

Já o bolsista de apoio técnico, por estar imerso nas atividades do museu, entendendo sua dinâmica e suas possibilidades, submeteu um projeto de mestrado ao edital do Programa de Pós-graduação em Educação da Universidade Federal de Uberlândia (PPGED/FACED/UFU) no ano de 2011, propondo uma investigação que tem como palco de estudo o Museu de Biodiversidade do Cerrado. Assim, em decorrência da aprovação do bolsista no processo seletivo do PPGED/FACED/UFU o projeto citado está se encaminhando, e ganhando forma, alargando-se de experiências e teorias vivenciadas ao longo do curso de mestrado. A pesquisa proposta veio do desdobramento de sua participação ao longo de dois anos no projeto de modernização do MBC, acompanhado de inquietações dadas no trabalho cotidiano naquele espaço e nas leituras sobre museus de ciências. Deste modo a problemática da pesquisa, como sugere Luna (1989), surgiu a partir da teoria que apresenta lacunas no conhecimento da realidade o que faz aparecer assim novos problemas de pesquisa.

A pesquisa apresentada considera a importância e a centralidade da interatividade como uma nova forma de comunicação dos museus de ciências, que procura garantir o engajamento cognitivo e intelectual dos usuários por meio de uma interação física dinâmica, não restrita a simples toques, relacionando ação a emoção, a afetividade Cazelliet al. (1999). O enfoque do estudo se dá na interação entre sujeitosobjetos, sujeitos-sujeitos pautando-se nos princípios sobre a interatividade presente na bibliografia especializada em museus de ciências.

Tendo em vista a necessidade de dar continuidade à modernização do espaço, a fim de torná-lo mais adequado à realidade o mundo contemporâneo, o trabalho propõe por meio da criação de 
Gustavo Lopes Ferreira, Helena Morais Pacheco, Luiz Paulo Costa e Silva, Fernanda Helena Nogueira-Ferreira \& Daniela Franco Carvalho

um artefato $^{7}$ interativo inserido à exposição permanente do MBC, analisar sua potencialidade na apropriação do discurso científico pelo visitante.

Nesta perspectiva pretende-se trabalhar a relação museu-público, temática esta que se tornou um assunto muito presente nos trabalhos relacionados à área de educação em museus, passando a preocupar-se "com o alcance, abrangência e a qualidade de ações promovidas pelo espaçomuseal" segundo Gruzman e Siqueira (2007).

Diante dessas perspectivas futuras apresentadas pelos bolsistas, pode se perceber os ricos frutos que o engajamento no projeto de modernização produziu, servindo como base para uma reflexão acerca do impacto desse empreendimento. Ao aventurar-se pelos caminhos até então desconhecidos da educação não formal, os bolsistas transformaram e foram transformados pessoal e profissionalmente pelo museu, num relacionamento em que resguardadas suas peculiaridades, produziu direcionamentos futuros que lhes permitem se identificar agora como profissionais atuantes em museu de ciências, conscientes de seu papel na sociedade atual.

\section{Considerações finais}

O texto apresentado propôs de forma sucinta abarcar alguns questionamentos travados no trabalho no museu de ciências, trazendo no centro do debate a incipiência com que a educação em museus é tratada na formação inicial de professores. Para isto, confrontou-se o que está expresso no Projeto Político Pedagógico com as ementas de algumas disciplinas do curso de Ciências Biológicas da Universidade

\footnotetext{
7 O sentido deste termo encontra-se no trabalho de Nascimento e Ventura (2001) que o define como: “é um objeto que não existe de fato sendo projetado especialmente para aexposição. Dentro dos museus de ciências ele substitui o conceito científico ou o dispositivo técnico, considerados difíceis ou mesmo impossíveis de serem apresentados. $\mathrm{O}$ artefato é então um ser imaginário, que o visitante nunca viu nem nunca verá fora do espaço da exposição, construído para permitir a compreensão da realidade do verdadeiro dispositivo técnico ou da descoberta científica. O contexto do artefato é também uma simulação de uma realidade que não encontramos em lugar algum, mas que subentende o ponto de vista do conceptor, que ele pretende pedagogicamente passar para o visitante".
}

Olh@res, Guarulhos, v. 1, n. 2, p. 247-268, Novembro, 2013. 
Espaços não formais de educação como campo de atuação do licenciado em ciências biológicas

Federal de Uberlândia, bem como relacionando a prática curricular vivenciada pelos bolsistas estudantes e egressos do curso.

Cabe repensar o que fora apresentado por tal análise, diante da constatação de que muito ainda precisa ser feito no sentido de trazer ao debate durante a graduação as possibilidades de atuação em espaços não formais de educação, não só no curso de Ciências Biológicas, mas nas demais áreas das ciências da natureza. Estar atento a esta necessidade torna possível formar profissionais comprometidos com tais espaços que sejam capazes de compreendêlos em sua totalidade, buscando entre tantas possibilidades, uma melhor interlocução com a sociedade.

Pode-se pensar na melhor maneira em se agregar tal discussão à formação inicial, entende-se que para isto não são as práticas pontuais, desprovidas de reflexão e discussões que alcançarão essa almejada sólida formação. Ao contrário, é preciso promover meios de interlocução entre os estudantes e o museu logo no início do curso de graduação, ou mesmo antes, formando alunos da Educação Básica para atuarem como mediadores em museus de ciências. Esta não é uma realidade distante, pois em muitas instituições existem programas de sucesso com esta natureza.

No caso da realidade apresentada pelo trabalho, alguns passos em direção ao incremento de estudos sobre espaços não formais de educação e a divulgação científica na formação inicial de professores já foram dados, basta observar o Projeto Pedagógico o qual faz, em vários momentos, referência a espaços extraescolares como campo de atuação profissional. $\mathrm{O}$ que de fato precisa haver é um engajamento de professores e estudantes que gerando uma demanda, possam propor a real efetivação do que está no documento, para que juntos valorizem também os ambientes formativos que são os museus de ciências. Incluindo-se nisto, viver novas possibilidades de reflexão que uma prática extraescolar fornece, tratando tais ambientes como um campo promissor de profissionalização.

Olh@res, Guarulhos, v. 1, n. 2, p. 267-288, Novembro, 2013. 
Gustavo Lopes Ferreira, Helena Morais Pacheco, Luiz Paulo Costa e Silva, Fernanda Helena Nogueira-Ferreira \& Daniela Franco Carvalho

É importante deixar claro que não está se defendendo a prevalência de profissionais formados em áreas afins as Ciências Naturais como os únicos e necessários aos museus de ciências, pelo contrário, reivindica-se que haja uma diversidade de áreas, como: designers, arquitetos, engenheiros, museólogos, historiadores, artistas, entre tantos outros que se ligam direta ou indiretamente. É neste imbricamento de pessoas com seus diferentes olhares e contribuições que a instituições se fortaleceme, consequentemente, a divulgação científica e a sociedade como um todo.

Dentre tantas possibilidades vividas pelos bolsistas, ora na concepção da modernização do espaço museal buscando alternativas inovadoras que modificasse a forma de interação do museu com o visitante, ora interagindo com os demais integrantes do projeto, foi possível experimentar outras e inusitadas experiências que assim somadas conjugaram-se para moldar suas formações pessoais e profissionais. Em certa medida, a sedução por este espaço fez com que todos pudessem se envolver com a proposta e não conseguirem mais se distanciar desse lugar de encantamentos.

Olh@res, Guarulhos, v. 1, n. 2, p. 247-268, Novembro, 2013. 


\section{Referências bibliográficas}

BRIDI, J. C. A. Orientação de Iniciação Científica: algumaspossibilidades. In: CONGRESSO NACIONAL DE EDUCAÇÃO-EDUCERE, 10., 2011, Curitiba. Anais... Curitiba: PUCPR, 2005. p. 11361-11375.

CAZELli, S. Alfabetização Científica e os Museus Interativos de Ciência. Dissertação (Mestrado em Educação) - Programa de Pós-Graduaçãoem Educação da PUC-RJ, Rio de Janeiro, 1992. et al.. Tendências Pedagógicas das Exposições de umMuseu de Ciência. In: ENCONTRO NACIONAL DE PESQUISA EMEDUCAÇÃO EM CIÊNCIAS, 2., 1999,Valinhos. Anais... São Paulo, p. 1-12,1999.

CHELINI, M. J.; LOPES, S. G. B. C. Exposições em museus de ciências: reflexões e critérios para análise. Anais do Museu Paulista: História e Cultura Material, São Paulo; N. Sér, v.16,n.2, p. 205-238, jul.- dez 2008.

CUNHA, M. B.; GIORDAN, M. A divulgação científica como um gênero de discurso: implicações na sala de aula. In: ENCONTRO NACIONAL DE PESQUISA EM EDUCAÇÃO EM CIÊNCIAS, 7., 2009, Florianópolis. Atas... Florianópolis, 2009. 1 CDROM.

CURY, M.X. Estudo sobre Centros e Museus de Ciência: subsídios para uma política de apoio.Cadernos do Museu da Vida, São Paulo,p. 60-70, 2001/2002.

DIERKING , L. D.: Lições sem limite: como oaprendizado por livre escolha vem transformando a educação em ciência etecnologia.História, Ciências, Saúde Manguinhos, Rio de Janeiro; v. 12 (suplemento), p. 145-60, 2005.

Ementas das Disciplinas do Núcleo Pedagógico do Curso de Ciências Biológicas-UFU. Disponível em<http://www.portal.ib.ufu.br/node/116>. Acesso em 20/07/2012. GRUZMAN, C.; SIQUEIRA, V. H. F. O papel educacional do Museu de Ciências: desafios e transformações conceituais. Revista Electrónica de Enseñanza de lasCiencias, vol. $\quad 6, \quad$ n. $\quad 2, \quad$ p. 402-423. 2007. Disponível em<http://www.saum.uvigo.es/reec/volumenes/volumen6/art10_vol6_n2.pdf>. Acesso em 25/07/2012.

JACOBUCCI, D. F. C. Contribuições dos espaços não formais de educação para aformação da cultura científica. Em Extensão,Uberlândia,v. 7,n. 0, 2008. Disponível 
Gustavo Lopes Ferreira, Helena Morais Pacheco, Luiz Paulo Costa e Silva, Fernanda Helena Nogueira-Ferreira \& Daniela Franco Carvalho

em<http://www.revistadeextensao.proex.ufu.br/viewarticle.php?id=62>. Acesso em 12/07/2012.

LUNA, S. V. O falso conflito entre tendências metodológicas. In: FAZENDA, I. (org.). Metodologia da Pesquisa Educacional. São Paulo: Editora Cortez, p. 23-33, 1989.

MARANDINO, M. A formação inicial de professores e os museus de Ciências. In: SELLES, S.E.; FERREIRA,M.S. (orgs.). Formação docente em Ciências: memórias e práticas. Rio de Janeiro: EdUFF, p. 59-76, 2003.

MARTINS, M. L. Ensino-pesquisa-extensão como fundamento metodológico na construção do conhecimento na universidade. Bauru: texto publicado pelo departamento de psicologia Da UNESP-Universidade Estadual Paulista campus de Bauru. Disponível em: <http:// www.fc.unesp.br.> Acesso em: 27 set. 2012.

NASCIMENTO, S. S.; VENTURA, P. C. S. Mutações na construção dos museus de ciências. Pro-posições, Campinas, vol 12, número 1 (34), p.126-138, 2001.

OVIGLI, D. F. B.; FREITAS, D. Contribuições de um centro de ciências para a formação inicial do professor. In: SIMPÓSIO NACIONAL DE ENSINO DE CIÊNCIA E TECNOLOGIA, 1, 2009, Ponta Grossa. Anais... Ponta Grossa: UTFPR, p. 695-708, 2009.

OVIGLI, D. F. B. Prática de ensino de ciências: o museu como espaço formativo. Rev. Ensaio, Belo Horizonte, v.13, n.03, p.133-149, set-dez 2011.

Projeto Político Pedagógico do Curso de Ciências Biológicas - UFU, 2006. Disponível em<http://www.portal.ib.ufu.br/sites/ib.ufu.br/files/Anexos/Bookpage/Projeto\%20Pol\% C3\%ADtico\%20Pedag\%C3\%B3gico\%20-\%20Curr\%C3\%ADculo\%202006-1.pdf>.

Acesso em 12/07/012.

QUEIROZ, G. P. Parcerias na formação de professores de ciências na educaçãoformal e não-formal. Cadernos do Museu da Vida, p. 80-87, 2001/2002.

SOUZA, A. V. S. A Ciência Mora Aqui: Reflexões Acerca dos Museus e Centros de Ciência Interativos do Brasil. Dissertação (Mestrado em História da Ciência e da Técnica e Epistemologia do Conhecimento Científico) - IQ/UFRJ, Rio de Janeiro, 161f., 2008 .

WAGENSBERG, J. PrincipiosFundamentales de la Museologia Científica Moderna.

Alambique - Didáctica de LasCienciasExperimentales, n. 26, p. 15 - 19, out/nov, 2000 .

Olh@res, Guarulhos, v. 1, n. 2, p. 247-268, Novembro, 2013. 